\title{
To Whom Are You Writing? Examining Audience in L2 Textbook Writing Activities
}

\author{
Thamer Kalfut ${ }^{1}$ \\ ${ }^{1}$ Department of English, Oklahoma State University, Stillwater, USA \\ Correspondence: Thamer Kalfut, Department of English, Oklahoma State University, Stillwater, USA.
}

Received: August 11, 2021

Accepted: September 24, 2021

Online Published: September 28, 2021

doi: 10.5539/elt.v14n10p105

URL: https://doi.org/10.5539/elt.v14n10p105

\begin{abstract}
A sense of audience is important in the development of student writing (Many \& Henderson, 2005). Research shows students need to consider an audience's attitudes, beliefs, andexpectations to be effective writers (Midgette, Haria, \& MacArthur, 2007). Therefore, students need learning opportunities in L2 classrooms to develop this ability. Yet, the incorporation of audience in L2 textbook writing activities has not been sufficiently addressed. This study examined textbook activities to whom students write based on parameters of audience influence proposed by Grabe and Kaplan (1996, 2014). Writing prompts from six high school textbooks inSaudi Arabia were analyzed. The results indicate prompts instruct students to write to a single reader, known/unknown readers, as well as write about general topics. However, prompts do not provide information for students about three parameters (age, gender, and social status) which are necessary ingredients in developing a writer's sense of audience and play a significant role on textual variations. This study also modified a model of audience that can be used for textbook evaluation. The findings benefit textbook developers and teachers by motivating them to consider parameters of audience influence when they design lessons and materials for L2 writingclassrooms.
\end{abstract}

Keywords: textbook evaluation, audience, writing activities, second language writing

\section{Introduction}

Writing is a dialogue between writers and audiences (Block \& Strachan, 2019; Harvey, 1997; Hyland, 2001; Mangelsdorf, Roen, \& Taylor, 1990; Many \& Henderson, 2005; Shaw \& Weir, 2007); thus, audience plays a significant role in helping writers decide on language use, content of writing, and text formality (Durán, 2016; Harmer, 2004; Hedge, 1988; Raimes, 1983).

Hyland (2001) examined 240 articles from various disciplines and found writers used "we" to build a close relationship with audiences and maintain peer solidarity. Hyland commented, using "we" is "a strategy that stresses the involvement of the writer and reader in a shared journey of exploration, although it is alwaysclear who is leading the expedition" (p. 560). Hyland's study illustrates writers applied a certain language to address audiences because they have an awareness of "parameters of audience influence" (Grabe \& Kaplan, 1996, p. 207; see explanation below). One of the parameters is social closeness between writers and audiences which plays a crucial role in shaping a text. Ramanathan and Kaplan (1996) state when L2 students know who their readers will be, this knowledge helps them to develop a sense of audience to present voices clearly. The above research shows the importance of a sense of audience for producing an excellent text. Also, a sense of audience is essential in writing instruction (Ramanathan \& Kaplan, 1996). Yet, how a sense of audience has been transferred to L2 textbooks is still unclear.

L2 textbooks are the main teaching materials utilized in classrooms (Aljouei \& Alsuhaibani, 2018; Nunan, 1999). Since textbooks are the fundamental building blocks of ELT programs for both students and teachers (Sheldon, 1988), it is anticipated textbooks provide learning opportunities for students to develop a writing ability especially a sense of audience. According to previous research, writers need to consider an audience's attitudes, beliefs, and expectations to be effective writers (Ede \& Lunsford, 1984; Midgette, Haria, \& MacArthur, 2007). Yet, the review of current research (Al-Harbi, 2017; Aljouei \& Alsuhaibani, 2018; Al-Qadi \& Al-Qadi, 2015; Cahyati, Srijono, \& Hum, 2018; Habib \& Umar 2006; Hanifa, 2018; Kobayakawa, 2011; You, 2004) shows that the integration of audience in textbook writing activities has not been sufficiently established. The lack of opportunities in textbooks to develop a sense of audience can restrain students' writing ability. 
In Saudi Arabia, the Ministry of Education has recently issued English language textbooks to be used for high school. The Ministry set up learning objectivesper grade level for writing skill development. Audience is one of the objectives, as shown in Table 1. Likewise, all teachers' manuals of Traveller series textbooks 1-6 emphasize the importance of raising students' awareness of audience. One manual lists audience concerns in the writing section: "The writer must take many things into consideration: handwriting, spelling, punctuation, paragraphing, purpose, audience and syntax. For this reason, the course [textbook] has paid particular attention to [writing]" (Traveller 1 Teacher's Manual, p. 4). The other Traveller textbooks have similar statements, which indicate that audience is a main component of each textbook. In addition, it is important to have a sense of audience in the Saudi Arabian context because considerable social parameters (e.g., gender, age, and social status) play a vital role in shaping people's interactions, due to Arabic traditions. Tawalbeh and Al-Oqaily (2012) gave Saudi and American college students a written discourse completion test and found Saudis used different request strategies when communicating with people of low/high social statuses, demonstrating the impact of social status on Saudi communication.

Table 1. Learning Objectives of Writing Skills Set Up by Ministry of Education (2014-2020)

\begin{tabular}{|c|c|c|}
\hline No. & Learning objectives of writing skills $\mathrm{s}^{\mathrm{a}}$ & Grade \\
\hline$\overline{1}$ & $\begin{array}{l}\text { "Deal with specific aspects of writing (paragraphing, purpose, } \underline{\text { audience }}, \\
\text { cohesion, coherence)" (p. 57). }\end{array}$ & 10th \\
\hline 2 & $\begin{array}{l}\text { "Deal with specific aspects of writing (paragraphing, purpose, } \underline{\text { audience }} \text {, } \\
\text { register, cohesion, coherence)" (p. 64). }\end{array}$ & 11 th \\
\hline 3 & $\begin{array}{l}\text { "Deal with specific aspects of Writing (paragraphing, purpose, } \underline{\text { audience, }} \\
\text { style, register, cohesion, coherence, organisation)" (p. 70). }\end{array}$ & 12 th \\
\hline
\end{tabular}

Note. ${ }^{a}$ emphsis added

Despite the importance of heightening students' awareness of audience when developingwriting skills, Saudi high school English language textbooks have not undergone thorough investigation to determine whether and how writing activities align with the Ministry's learning objectives of writing skills. Therefore, this study sought to identify whether and if so how high school English language textbook developers in Saudi Arabia construct a sense of audience in the writing activities. In particular, this study examined to whom students write. Analysis adapted Grabe and Kaplan's $(1996,2014)$ model of audience parameters to analyze writing prompt activities within the broad ecology of a learning unit. Findings can benefit textbook developers by offering them parameters for designing materials. They also raise teachers' awareness of the relationship between a writer and audience in writing activities offered in L2 textbooks, and in consequence, the findings can contribute to the effective teaching in L2 classrooms.

\section{Literature Review}

\subsection{Model for Parameters of Audience Influence}

To gain insight into the development of student writing ability as it relates to engagement with various audiences, it is necessary to identify parameters related to prospective audiences. Grabe (1990) and Grabe and Kaplan (1996, 2014) suggest a model called parameters of audience influence that is recognized in research related to the writing context (see Cho \& Choi, 2018; Fongoqa, 2002; Mthembu-Funeka, 2009; Shaw \& Weir, 2007). This model contains five parameters which have an impact on textual variations. The first is the number of text readers. Writers write for oneself, an individual, a small or wide group of people, or the public. The second is whether readers are known or unknown. It refers to the degree of closeness between writers and audiences, such as whether they are colleagues or strangers. The third is the social status of a person (e.g., a well-known scholar). An audience has a higher, equal, or lower status than the writer. The fourth is whether a writer and audience share background knowledge. When a writer and the audience are familiar with an event in a certain cultural context, the writer provides less information because he/she assumes readers have this shared knowledge. The last is whether a writer and audience share specific topical knowledge. This knowledge leads a writer to utilize general versus professional terms. According to He and Shi $(2008,2012)$, specific topical knowledge also refers to specific cultural knowledge where topics are only relevant to a certain community. In a nutshell, the model provides five factors that writers should take into account while writing a text to address audiences properly.

Despite the impact of Grabe and Kaplan's $(1996,2014)$ model in the teaching of writing, it still lacks two aspects that have an impact on developing a sense of audience. The first is gender of audience. Johnson (1992) found a male addressee received more closing compliments from L2 student writers than a female addressee. The second is 
age of audience. A study by Frank (1992) found fifth grade students adapted writing according to their audience ages; their writing to a third-grade audience wasmore successful than to an adult audience because they succeeded in considering a third-grade audience's expectations more than an adult's. Therefore, it is significant to consider these two key aspects in examining the audience concept in the Saudi textbooks because Saudi Arabia has a sensitive communication system build on Arabic values, where gender and age play a role in shaping people's interactions. The adding of these aspects to Grabe and Kaplan's model of audience will also make it more comprehensive (see Figure 1). These two aspects and the other parameters suggested by Grabe and Kaplan are examined to observe whether they have been taken into account when developing writing activities in L2 textbooks in Saudi Arabia.

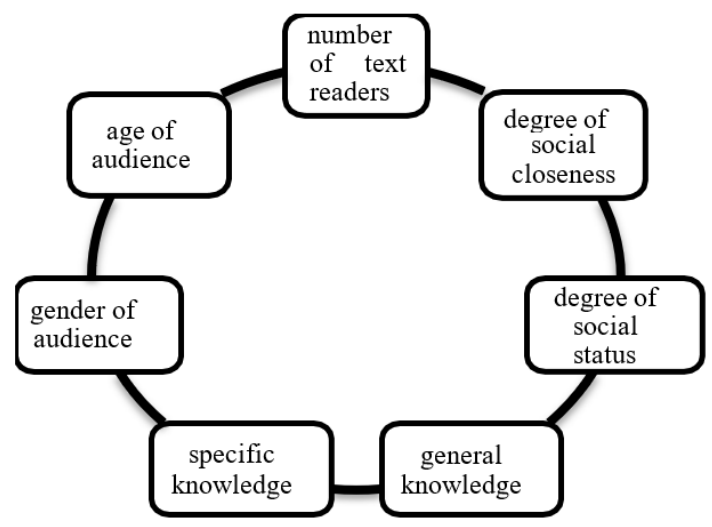

Figure 1. Parameters of Audience Influence (Adapted from Grabe \& Kaplan 1996)

\subsection{Research on Parameters of Audience Influence in L2 Textbooks}

The examination of audience in L2 textbook writing activities began in the late 1990s when Johnston (1996) studied, in part, whether a sense of audience was encouraged in seven ESL global textbooks. He found a teacher's textbook provided information about the importance of audience in L2 writing, but a student's textbook offered limited writing activities to address audience. This lack of audience in textbooks was argued to limit students' understanding of intended readers and led to the question: to whom are they writing?

Although Johnston's findings suggest the need for a broader investigation into audiencewithin L2 textbook writing activities, previous research has neglected studying this important issue. Instead, much research on L2 textbooks have other aims. First, numerous studies have evaluated the weaknesses and strengths of a textbook based on a Likert scale checklist (e.g., learning objectives, layout, etc.), but they have not examined the incorporation of audiences in textbooks (Al-Hajailan, 1999; Alhamlan, 2013; Al-Harbi, 2017; Alharbi, 2015; Aljouei \& Alsuhaibani, 2018; Almalki, 2014; Al-Sowat, 2012; Ahour, Towhidiyan, \& Saeidi, 2014; Jahangard, 2007; Hammad, 2014; Hanifa, 2018; Henriques, 2009; Zohrabi, Sabouri, \& Behroozian, 2012). Second, limited studies have examined the incorporation of writing activities in L2 textbooks, but findings are not specific to audience in L2 writing (Al-Qadi \& Al-Qadi, 2015; Cahyati, Srijono, \& Hum, 2018; Habib \& Umar 2006; Kobayakawa, 2011; You, 2004).

A few studies have examined both audience and writing activities in textbooks (Ramanathan \& Kaplan, 1996; Liao \& Chen,2009). Ramanathan and Kaplan (1996) examined the incorporation of "audience" and "voice" in ten writing textbooks used in an undergraduate composition program in the U.S. These textbooks are used by native and non-native students. The researchers found a serious problem: textbooks rely on shared cultural knowledge that non- native students do not have. For example, non-native students are asked to write about gun control, but they are unfamiliar with this topic because they have minor gun-related crimes in their nations. These topics disadvantage L2 students to involve with the textbooks and hinder students' development. Except knowledge of topics, Ramanathan and Kaplan's study does not examine other parameters mentioned above by Grabe and Kaplan and other researchers. Another study was carried out by Liao and Chen (2009). They conducted a comparison investigation of argumentative rhetorical strategies offered in textbooks used in Taiwan: three high school Chinese composition textbooks and three college English composition textbooks. One of the nine questions in this study was about the audience roles. They found both the Chinese and English textbooks draw student attention to the importance of audience in writing an effective text, but the English textbooks provide more details about potential audiences. The study reported an English textbook gives students opportunities to address four roles of audiences: supportive, neutral, resistant, and completely resistant. Each role requires a certain treatment in argumentative writing. When a writer and supportive audiences have a similar view on a topic, a writer may only need to state that 
view without discussing the opposing opinion. When students write to neutral audiences, they are instructed to fairly summarize the opposite opinions and then disprove them. For the resistant audiences, the English textbook instructs students withhold their view until the end of the argument. Finally, regarding completely resistant audiences, the English textbook suggests students highlight the common goals and beliefs shared by the writer and their audience. However, the Chinese textbooks do not provide such details while discussing audience. They concluded the English textbooks are audience-oriented, but the Chinese textbooks are less audience-oriented. This example shows how the roles of audience inform the selection of argumentative writing strategies to fulfill a particular purpose. Liao and Chen's study did not examine other parameters mentioned by Grabe and Kaplan and other researchers except roles of audience. In short, the above two studies have examined only one parameter of audience influence. They have not educated us about the incorporation of other parameters of audience influence in L2 textbooks. Furthermore, Saudi Arabia has a communication system which is influenced by Arabic traditions. In this system, gender and age are important in shaping people's interactions. Therefore, it is important to consider the concept of audience in the Saudi textbooks based on these parameters. Thus, it seems crucial to shed light on how these parameters have been addressed in high school L2 textbooks. Also, Liao and Chen show that audience is addressed differently in Chinese textbooks and English textbooks. It would be interesting to discover whether L2 textbooks in Saudi Arabia are audience-oriented, matching English textbooks, or less audience-oriented, similar to Chinese textbooks. Therefore, there is a need to conduct further research to address this issue to broaden our understanding of the parameters of audience influence offered in L2 Saudi Arabian textbooks.

Due to the importance of parameters of audience influence in the development of student writing ability and the lack of studies addressing this matter in high school L2 textbooks as part of school curriculum, this study addressed one research question:

To what extent do writing prompts in the Traveller series textbooks in Saudi Arabia take into consideration parameters of audience influence?

\section{Method}

\subsection{Data Collection (Textbook Description)}

The collected data are six students' textbooks called the Traveller series. They are designed for high school (10th-12th grades) based on the guidelines of the Ministry of Education in Saudi Arabia for the 2017-2018 academic year. The proficiency levels are based on the Common European Framework of Reference for languages (CEFR).

\subsubsection{The Structure of a Whole Learning Unit}

The textbooks are designed based on an integrated approach that focuses on teaching the four skills. Also, the textbooks include sections about grammar and vocabulary in each unit. Each textbook contains four to ten learning units. Each unit is built around one topic. There are several lessons in each unit and they are thematically connected to the general topic. Figure 2 shows five lessons offered in Traveller 1-Unit 1. The length of each lesson is two pages. The lesson consists of several sub-sections: vocabulary, pronunciation, grammar, reading, listening, speaking, writing, and practice. The theme is "Youthculture." A writing section appears at the end of each writing lesson. Appendix A and B provide examples of two lessons (1C and 1E), which both contain writing sections. 


\begin{tabular}{|c|c|c|c|c|c|c|}
\hline \multicolumn{7}{|c|}{ Lesson $1 \mathrm{~A}$ What's up? } \\
\hline \multicolumn{2}{|c|}{ Section 1: Listening \& Reading } & Section 2: Vocabulary & Section 3: Grammar & Section 4: Practice & \multicolumn{2}{|c|}{ Section 5: Speaking } \\
\hline \multicolumn{2}{|c|}{3 Activities } & 1 Activity & 2 Activities & 2 Activities & \multicolumn{2}{|c|}{1 Activity } \\
\hline \multicolumn{7}{|c|}{ Lesson 1B Keep in touch } \\
\hline \multicolumn{2}{|c|}{ Section 1: Reading } & Section 2: Vocabulary & Section 3: Grammar & Section 4: Practice & \multicolumn{2}{|c|}{ Section 5: Speaking } \\
\hline \multicolumn{2}{|c|}{5 Activities } & 1 Activity & 3 Activities & 2 Activities & \multicolumn{2}{|c|}{1 Activity } \\
\hline \multicolumn{7}{|c|}{ Lesson IC That's me } \\
\hline $\begin{array}{l}\text { Section 1: } \\
\text { Vocabulary }\end{array}$ & $\begin{array}{l}\text { Section 2: } \\
\text { Grammar }\end{array}$ & $\begin{array}{l}\text { Section 3: } \\
\text { Practice }\end{array}$ & $\begin{array}{l}\text { Section 4: } \\
\text { Intonation }\end{array}$ & $\begin{array}{l}\text { Section 5: } \\
\text { Speaking }\end{array}$ & $\begin{array}{l}\text { Section 6: } \\
\text { Listening }\end{array}$ & $\begin{array}{c}\text { Section } 7: \\
\text { Writing }\end{array}$ \\
\hline 1 Activity & 1Activity & 1 Activity & 2 Activities & 1 Activity & 3 Activities & 3 Activities \\
\hline \multicolumn{7}{|c|}{ Lesson ID Good role models } \\
\hline \multicolumn{2}{|c|}{ Section 1: Reading } & Section 2: Vocabulary & \multicolumn{2}{|c|}{ Section 3: Grammar } & \multicolumn{2}{|c|}{ Section 4: Practice } \\
\hline \multicolumn{2}{|c|}{5 Activities } & 1 Activity & \multicolumn{2}{|c|}{3 Activities } & \multicolumn{2}{|c|}{2 Activities } \\
\hline \multicolumn{7}{|c|}{ Lesson IE Friendly faces } \\
\hline \multicolumn{2}{|c|}{ Section 1: Vocabulary } & Section 2 : Listening & \multicolumn{2}{|c|}{ Section 3: Speaking } & \multicolumn{2}{|c|}{ Section 4: Writing } \\
\hline \multicolumn{2}{|c|}{1 Activity } & 2 Activities & \multicolumn{2}{|c|}{1 Activity } & \multicolumn{2}{|c|}{4 Activities } \\
\hline
\end{tabular}

Figure 2. Example Unit Structure with Lessons, Sections, and Activities (Traveller 1)

The writing sections do not contain activities that are independent of other activities in the unit. Instead, the writing sections are part of a broader ecology of activities that build upon skills learned earlier in the unit. Figure 3 provides a concept map of how activities from Lesson 1C "That's me" are connected to the activities within the writing section. The arrows from section 1 to section 6 indicate each section is connected to the three activities in the writing section. Section 1 introduces phrases (e.g., is a big fan of to describe things that a student likes or dislikes. The same phrase is utilized in the reading passage in the writing section (e.g., I am a big fan of sport). This example illustrates the connection between the vocabulary section and the reading activity within the writing section. The reading passage demonstrates for students how a writer uses the above phrase to present himself. Therefore, it is assumed that the vocabulary section provides students with language tools that assist them in writing about themselves at the end of this lesson.

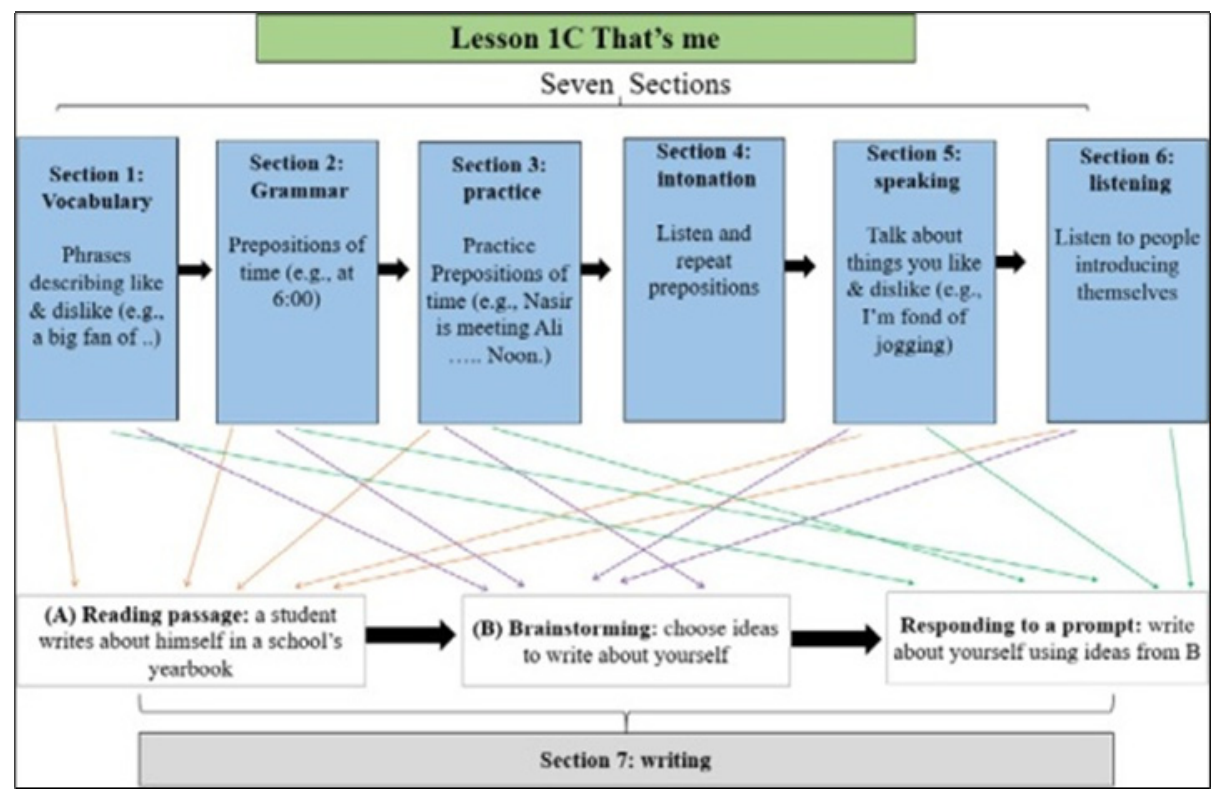

Figure 3. The Integration of All Activities into the Writing Section (Traveller 1) 
This study examined writing activities which appear within the writing section. Particularly, due to the purpose of this study (to whom students write), the focus was on analyzing writing prompt activities $(\mathrm{N}=49)$ which appear at the end of each writing lesson. Careful consideration is placed on how activities are integrated into the broader ecology of the textbook unit; thus, specific examples are extracted from the unit to show the interconnectedness between writing prompt activities and other activities.

\subsection{Data Analysis}

A mixed methods data analysis program called MAXQDA (2018) was used to conduct a content analysis of writing prompt activities appearing at the end ofeach writing lesson and then automatically count the frequency of activities in the textbooks. Also, writing activities and the TIP boxes in the writing sections in all textbooks were examined to observe if a sense of audience has been taken into consideration in the writing sections. In addition, learning activities (listening, speaking, reading, grammar, etc.) in one textbook from each grade (Traveller 1 from the 10th grade, Traveller 3 from the 11th grade, and Traveller 5 from the 12th grade) were analyzed to study the integration of audience in the broader ecology of a learning unit.

Grabe and Kaplan's $(1996,2014)$ model, which has five parameters of audience influence, was utilized to analyze the data. The parameters are: number of text readers, degree of social closeness, degree of social status, shared background knowledge, and shared specific topical knowledge. Two parameters (gender of audience and age of audience) were added due to past research that show these parameters have an influence on the quality of writing (see Appendix C). Then, Brown's (2007) classification method of analyzing a language lesson in an L2 textbook was adapted. Brown classifies activities offered in the lesson based on a general taxonomy of language teaching strategies. Similarly, in the current study, every writing activity was classified based on each parameter and its sub-parameters. One category called "Not mentioned" was created for instances in which information is not available in the activity to decide on the parameter. To illustrate the analysis, five examples of writing activities are shown in Appendix D. An automatic random selection of ten activities ( $20 \%$ of data) was employed for intra-rater reliability. The percentage of coding consistency is shown in Table 2 below.

Table 2. Percentages of Intra-rater Reliability of Parameters of Audience Influence

\begin{tabular}{ll}
\hline Parameters & Percentage \\
\hline Number of text reader & 100 \\
Social closeness & 90 \\
Social status & 100 \\
Knowledge of topic & 100 \\
Gender of audience & 100 \\
Age of audience & 80
\end{tabular}

In the analysis of writing activities, several aspects of coding were addressed. Regarding the parameter "degree of social status," previous research indicates social status is "not only situation-specific but also culture-specific" (Economidou-Kogetsidis, 2012, p. 2267). Elders in certain communities must be treated with a high respect due to its local culture toward seniors. This view is applicable to Saudi Arabia, where people show respect to elders. Therefore, in this current study, when a reader of a text is an older person, this activity was coded as "Higher." For example, an activity in the Traveller series textbooks asked students to write to an elder person (a father of your friend) and was coded under "Higher."

The parameter "background knowledge of topic" in this study refers to assigned writing topics in the textbooks. Similar to past research mentioned in the literature review section, in this study, knowledge could be either general knowledge or specific knowledge.

General knowledge of topics refers to knowledge that many people in the world have as shown in this example: "write a paragraph explaining why you want to learn English" (Traveller 3, p. 11). So, this is a general topic that learners can write about regardless of their nationalities. On the other hand, specific knowledge of topics refers to knowledge that a certain group of people possess and can be broken down into two types. The first is cultural knowledge of certain events that belong to a certain community, such as Saudi Arabia. The second is topical knowledge of a scientific field, such as mechanical engineering. Therefore, a writing prompt in the textbooks was coded under one of the above categories of knowledge.

From the content analysis of writing activities concerning the parameter "gender of audience," two distinctions were made. First, a certain category called "Pronoun Usage to Indicate Either Gender" was created to code an activity which appeared several times, as shown in this example: "A friend of yours has recently moved away to 
another city. Write a letter to him/her with all your news" (Traveller 3, p. 43). Second, activities which used male names (e.g.,Victor) were coded under the category "Male."

Regarding the parameter "age of audience," since these L2 textbooks are written for high school students, it is assumed that their friends are also in the same age. For this reason, every writing prompt in the textbooks instructs students stating "write to your friend" was coded under the category "School Age." When information indicates that a friend is an adult age, it is coded under "Adult Age." For example, write an email to your friend who will come to your country to study a master program (Traveller 1). This activity was coded under the category "Adult Age" because it is common sense that students in a graduate education level are adults.

When the Traveller series textbooks did not provide specific information about the age of readers (e.g., magazine readers), it was coded as "Not mentioned."

\section{Results and Discussion}

\subsection{Audience in Writing Prompts in the Writing Sections}

Table 3 shows the results that answer the research question of this study. It reports the numbers and percentages of parameters of audience influence offered in the six Traveller series textbooks. As mentioned previously, 49 writing activities were examined in this study. The following discussion focuses on the findings of writing prompt activities thatappear at the end of each writing lesson.

Table 3. The Number and Percentage of Parameters of Audience Influence in Traveller Series

\begin{tabular}{lll}
\hline Sub-parameters & N & $\%$ \\
\hline Paramerer $1:$ n
\end{tabular}

\section{Parameter 1: number of text readers}

(1) A single person $\quad 25$

(2) The public

$25 \quad 51$

(3) Not mentioned

$10 \quad 20.4$

Parameter 2: degree of social closeness

$\begin{array}{lll}\text { (1) Known reader } & 20 & 40.8\end{array}$

(2) Unknown reader $\quad 15 \quad 30.6$

(3) Not mentioned $\quad 14 \quad 28.6$

Parameter 3: degree of social status

$\begin{array}{lll}\text { (1) Higher reader } & 7 & 14.3\end{array}$

(2) Equal reader $\quad 15 \quad 30.6$

(3) Lower reader $\quad 0 \quad 0$

(4) Not mentioned $\quad 27 \quad 55.1$

Parameter 4: background knowledge of topics

(1) General knowledge $\quad 40 \quad 81.6$

(2) Specific knowledge $\quad 9 \quad 18.4$

Parameter 5: gender of audience

(1) Female reader $\quad 0 \quad 0$

$\begin{array}{lll}\text { (2) Male reader } & 5 & 10.2\end{array}$

(3) Inclusive-gender (he/she) $\quad 7 \quad 14.3$

(4) Not mentioned $\quad 37 \quad 75.5$

Parameter 6: age of audience

(1) High school student age $\quad 11 \quad 22.4$

(2) Adult age $\quad 12 \quad 24.5$

(3) Not mentioned $\quad 26 \quad 53.1$ 


\subsubsection{Parameter 1: Number of Text Readers}

The number of audience determines the level of communication, where there are several levels, such as dyadic and mass communication (Cleary, 2004; Fielding, 2006). Writing for a single reader, interpersonal or dyadic communication, "occurs between two people, and forms the basic unit of communication ... [it] accounts for most formal, everyday communication transactions, including personal and intimate relationships" (Cleary, 2004, p. 9). On the other hand, writing for the public, mass communication, is "the transmission of a message to a mass audience... it is a one-way form of communication as feedback is limited. There is also no direct or personal contact between the sender and the receiver" (Cleary, 2004, p. 9). The vast majority of writing activities in the Traveller series instruct students to write to a single reader (51\%). This reader is a classmate, a friend, a relative, or a teacher. Comparatively, $20.4 \%$ of the writing prompts instruct students to write for the public, such as newsletter readers. It seems possible to conclude that the Traveller series in Saudi Arabia provide frequent learning opportunities for students to engage with the basic level of written communication, which involves writing for a single reader. It may be suggested that textbook developers in Saudi Arabia should increase the number of writing prompts offered in the textbooks to write for the public, and as a result, students will have more opportunities to practice writing for mass audiences.

Furthermore, the analysis of language activities in the broader ecology of a learning unit in the textbooks shows writing prompts are linked to the theme of a unit, but the activities do not inform students how to write for public audiences. The following example illustrates how students are asked to write for a public audience:

Read the rubric [writing prompt] below and write the [book] review (120-180 words). Goto the Workbook, p. 18.

An international magazine has asked readers to submit reviews of their favourite books. Describe your favourite book and say what you like about it. (Traveller 6, p. 27)

Despite this being a good example for writing to a real-world audience, the prompt has a single tie to other activities in the unit. Specifically, the prompt is connected to the theme of the unit. For example, students read a short passage about a dictionary and answer five questions which focus on reading comprehension. Also, in the speaking section, students are asked to discuss several types of books (e.g., art books, novels, etc.) that the school library may purchase. These examples show language

activities in the learning unit enrich students' content knowledge of books. However, these activities do not provide students with necessary content for understanding how to write to publicaudiences.

\subsubsection{Parameter 2: Degree of Social Closeness}

The results demonstrate writing prompts provide nearly similar learning opportunities for students to write for known readers (e.g., a friend) and unknown readers (e.g., international magazine readers). Table 2 shows the former appeared 20 times (40.8\%) and the latter appeared 15 times (30.6\%) in the Traveller series. A concern may arise whether students are aware of the importance of this type of social relationship in writing a text. A study by Al-Mohammadiand Derbel (2015) asked students to write an essay providing advice to a tourist who visits Oman. It was found students provide a lot of information in essays about Oman, but this information does not consider a foreigner's perspective. Students are unable to engage successfully with unknown readers. Therefore, since this current study provides evidence the Traveller series present opportunities for students to write for known and unknown readers, it is recommended to conduct further research about whether Saudi students are aware of this type of relationship. This research is not only applicable to students, but teachers may also be interviewed to shed light on this topic.

As mentioned previously, Grabe and Kaplan $(1996,2014)$ classified the degree of closeness into known and unknown readers. Liao and Chen (2009) mentioned roles of audiences: supportive, neutral, resistant, and completely resistant. Liao and Chen found an English textbook in Taiwan asked students to use different argumentative rhetorical writing strategies when they write to these roles. For instance, when a writer and supportive audiences hold similar opinions about a topic, a writer states an opinion without discussing the opposing view. In contrast, when a writer writes to neutral audiences, the writer discusses the opposite opinion and then disprove it. In the Saudi context, the analysis of activities offered in the broader ecology of a learning unit reveals that students have an opportunity to discuss arguable ideas, but without considering roles/closeness of audiences. Figure 4 presents a speaking activity where students argue the benefits and downsides of having mobile phones. This activity provides expressions (e.g., I disagree) for students to employ when they present their arguments orally to the class. The activity also suggests ideas (e.g., size, cost, people's health, etc.) that may boost their arguments. At the end of this unit, students are asked to respond to this prompt: 
Imagine that your school magazine has asked you to write your opinion about mobile phones. Write a paragraph using the ideas in the speaking activity. Your paragraph should be between 80-100 words. Go to the Workbook, p. 54. (Traveller 1, p. 65)

This prompt instructs students to write views about the advantages and disadvantages of mobile phone using ideas from the speaking activity. However, neither the speaking activity and nor the writing prompt instruct students to consider the roles/closeness of audiences in writing an argumentative essay. Therefore, it seems that this finding is contrary to Liao and Chen's (2009) study, which has suggested that the English textbook directed students to use argumentative strategies according to the audience roles. Thus, these results suggest the textbook provides expressions and ideas for students to utilize when presenting arguments orally, but without considering roles/closeness of audiences.

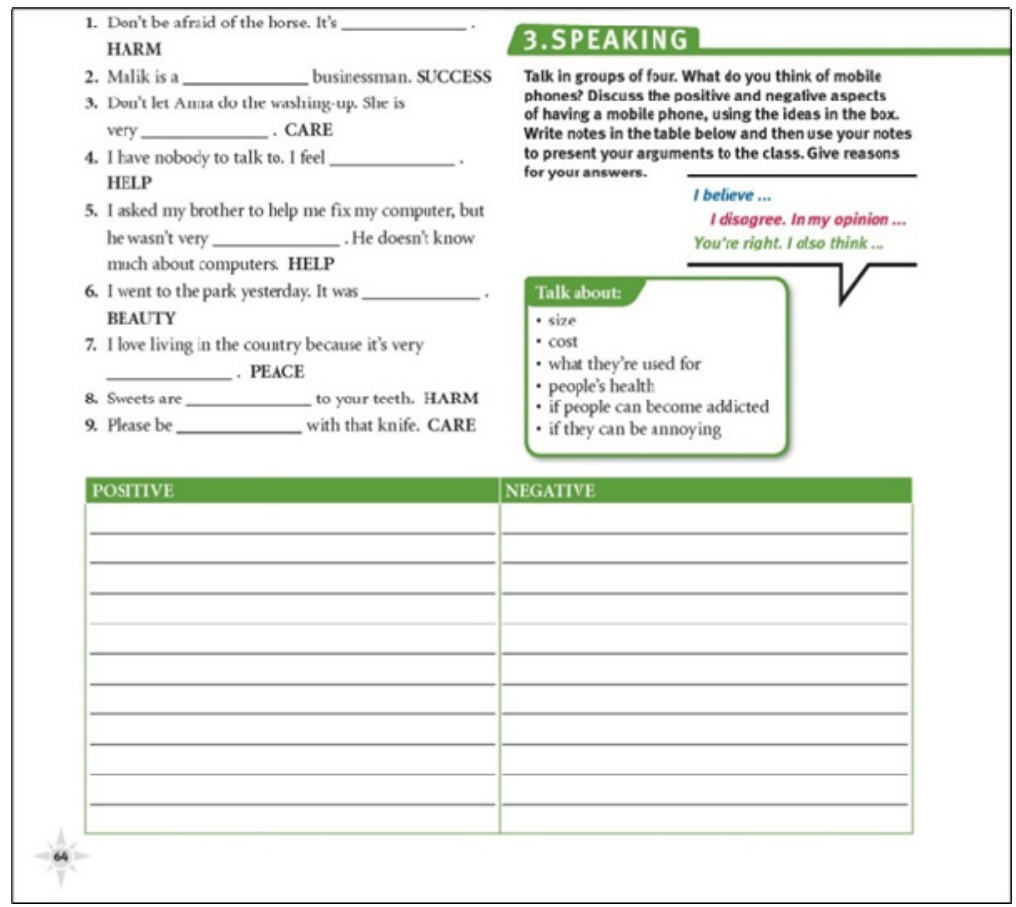

Figure 4. An Example of a Speaking Activity from Traveller 1, p. 64

\subsubsection{Parameter 3: Degrees of Social Status}

The degree of social status between a writer and an audience is often not mentioned in the writing prompts (55.1\%). In addition, students often write to readers who have equal relationship to them (30.6\%), particularly to their friends. A large number of previous studies have shown that the degree of social status has an effect on shaping people's interactions (Economidou-Kogetsidis, 2010; Nelson, Carson, Batal, \& Bakary, 2002; Lee, 2013; Tang \& Zhang, 2009). However, writing prompts in the Traveller series did not assist students in recognizing their social status relationships to their readers. For example, this prompt "write your own CV" (Traveller 2, p. 39) lacks the appropriate context. Students as job seekers have no idea about recruiters' social status. The textbooks did not provide effective learning opportunities for students to write for the audience who have a high authority. This may have a negative impact on their writing because "writers who do not identify their audience are very likely to miss their purpose in writing" (Al-Mohammadi \& Derbel, 2015, p. 204). To help students overcome this problem, it is recommended to add further information in the writing prompt to clarify the context of writing. This may help students to develop their sense of audience regarding their social status.

The finding displays the prompts do not mention the social status of an audience. A good example is, "Write a description of the person you admire most. Say why you admire this person and how he/she has influenced you (100-150 words)" (Traveller 3, p. 27). This prompt instructs students to write about an influential person. However, it does not provide information about the social status of audience. By examining the broader ecology of this learning unit, it wasfound the unit includes a language activity about the prior King of Saudi Arabia, Abdullah bin Abdulaziz (see Figure 5). Students read a short passage and complete missing words in the blanks. This activity is placed under the vocabulary and grammar section. Therefore, it is possible to argue that the purpose is to develop a student's linguistic competence. This activity does not aim to bring students' attention to the social status of the 
King. Thus, it seems that although the writing prompt and the vocabulary and grammar activity are in the same learning unit, they are not connected regarding the social status of audience. Given this, a better language activity would provide ideas and suggestions for students to consider an audience's social status. Consequently, students employ expressions when they write a letter to a minister of health, for example. In summary, it seems possible to conclude a social status of audience has not been incorporated in the other sections of a learning unit. Instead, textbook developers design activities to develop students' linguistic competence.

D. Read the text below and complete the gaps. Use only one word in each gap.

\section{A beloved King}

Born in Riyadh in 1924, the late King Abdullah bin Abdulaziz is one of the (1) respected figures in Saudi Arabia. King Abdullah, (2) father was the founder of the modern Kingdom, made drastic changes to the country while at the same time respecting the Saudi laws. (3) he became king in 2005, he launched a great project for the development of the country on many levels, (4) made him well-

known all over the world. As early as in 2005, he founded the King Abdullah
University of Science and Technology and the Princess Nourah bint Abdulrahman University for Women. In addition, through his scholarship programme, he sent more (5) 150,000 students to study abroad. He also boosted the economy in a variety of ways and promoted social changes. As time went by, King Abdullah's efforts for the development of his people became more and (6) intense. He died on 23 January 2015 and he will always be remembered as one of (7) country's greatest leaders.

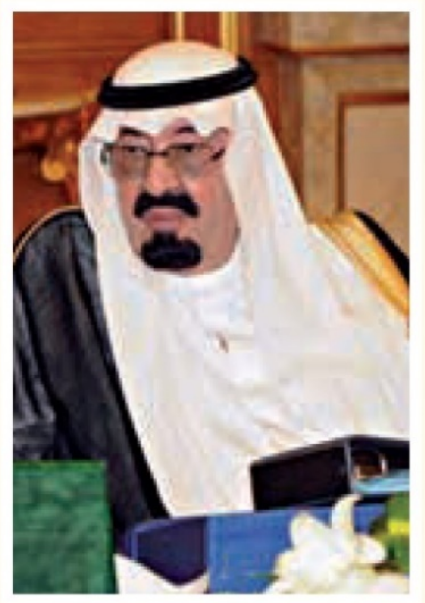

Figure 5. An Example of a Vocabulary \& Grammar Activity from Traveller 3, p. 35

\subsubsection{Parameter 4: Background Knowledge of Topics}

The prompts direct students to write about general topics (81.6\%), such as "Travelling by car is no longer a luxury but a necessity. Do you agree?” (Traveller 4, p. 27). It can be assumed that writers and readers share background knowledge of this topic, travelling.

The Traveller series includes a limited number of topics that require specific knowledge (18.4\%). Since the textbooks consist of general English, this finding is not surprising. Students write about local cultural topics (e.g., a popular festival in Saudi Arabia) more than writing about subject matter topics (e.g., environment). Since "writing about vacations and travel will be different from writing about economics, anthropology, physics, medicine, or law," (Grabe, 1990, p. 38), a question arises whether few opportunities to write about specific topics have a negative impact on developing writing skills. This needs further research. In short, the results indicate students have opportunities to write about general topics more than specific topics.

Several prompts in the Traveller series asked students to write about a Saudi cultural topic in an international magazine. However, it is still unrevealed how students write about specific cultural topics for international magazine readers. Previous research has revealed important findings regarding writing about a local cultural topic for unknown readers. Al-Mohammadi and Derbel (2015) found Omani students employed certain religious and cultural vocabulary and phrases in essays which are unfamiliar to a foreign visitor. Students lacked a sense of audience because they failed to consider whether foreign audiences understand their vocabulary and phrases which may result in misinterpretation of writing. They concluded instructing students to consider the audience's background develops critical thinking skills in choosing proper vocabulary, form, and style.

The results indicate several writing prompts in the Traveller series asked students to write about local cultural topics (e.g., write about a popular festival of Saudi Arabia in an English magazine). In examining the broader ecology of a learning unit, no evidence was found for associations between background knowledge of a topic and audience. The results show students read passages and listen to conversations to develop either reading comprehension or listening comprehension. As shown in Figure 6, students read a passage about a famous theme park in China, and answer questions to improve reading comprehension. However, when it comes to how the 
information about the Chinese park in the passage is delivered to meet audiences' expectations, textbook developers in Saudi Arabia do not emphasize this notion in the textbooks. It would have been more useful if they had asked questions about audiences, for example: Does a writer of the passage provide the readers enough information about the Chinese park? This question raises student awareness about the importance of background knowledge for audiences to understand a text. As a result, when students write about a popular festival in Saudi Arabia, they may realize what kind of information foreign audiences need to know.

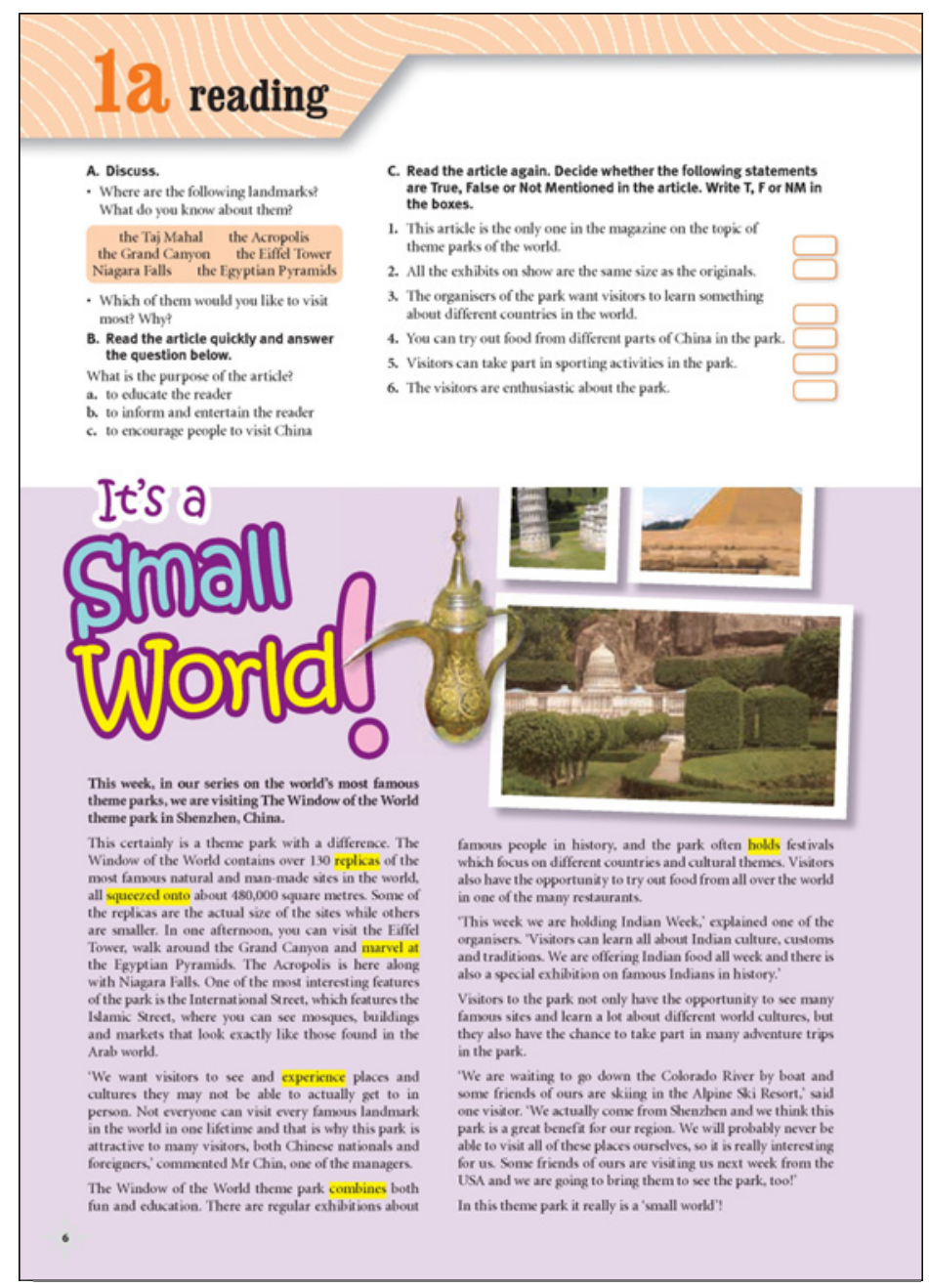

Figure 6. An Example of a Reading Activity from Traveller 3, p. 6

\subsubsection{Parameter 5: Gender of Audience}

The examination shows writing prompts do not mention the gender of audience (75.5\%). Furthermore, the prompts do not direct male students to write for female readers. Since culture and language cannotbe separated (Alptekin, 1993), it seems textbook developers avoid direct males to write for females because this conflicts with local culture. This claim may be supported by the fact that Saudi Arabia has an educational system where males and females learn separately (Alsharif, 2011; Wiseman, 2010). It is possible to conclude the lack of opportunities in the textbooks for males to write for females may not prepare students to be effective writers due to a lack of a sense of gendered audience. This conclusion contradicts with past research that emphasizes the importance of engaging students with real audiences (Cho \& Choi, 2018). Therefore, a question is: what is the impact of not encouraging male students to write for female readers? This question needs further research.

The results in this study contradict with previous research. It was found the textbooks use masculine gender-exclusive nouns (e.g., Victor). However, Vandergriff, Barry, and Mueller (2008) examined seven German undergraduate textbooks and found German textbooks avoid using gender-exclusive language. Another contradiction is the Saudi textbooks in this study rarely use gender-inclusive pronouns (e.g., he/she) (14.3\%), but Vandergriff et al (2008) found $90 \%$ of nouns in the textbooks were either gender-inclusive or gender-neutral language. These studies reported different conclusions regarding the representation of gender in the textbooks. 
As previously mentioned, $75.5 \%$ of writing prompts in the Traveller series do not mention the gender of audience. This may have a negative impact on a writer's sense of audience. Turner (1990) reviewed several studies in the 1970s and 1980s and found a social impact of language utilized in classrooms on students and teachers. It was found when teaching materials include language referring to males (e.g., he, men), students and teachers think of males. When materials contain words not specific for a certain gender (e.g., people), some students and teachers think of gender-balanced referents while others think of only male referents. Interestingly, when materials contain words not specific for a certain gender, male students do not think of female referents. Therefore, it could be argued that the lack of information about the gender of audience in writing prompts may create an image for male students that readers are often males, which is untrue in real life situations. Indeed, due to gender- sensitivity, it is a big challenge for textbook developers in Saudi Arabia to address this problem. A solution is to apply a gender-balanced language in textbooks. According to Turner (1990), "although research using gender specified language (women and men, he or she) that explicitly includes both females and males is sparse, it is believed by some researchers that this language form results in the most gender-balanced associations" (p. 58). As shown in Table 3, the textbooks include a gender-balanced language, but its percentage is too low (14.3\%). This percentage should be increased to provide better opportunities for students to develop a sense of a gendered audience.

This study indicates writing prompts do not direct male students to write for female readers. In other words, the textbooks do not use female names as readers of texts (e.g., write to Amal). However, the examination of different activities in the broader ecology of learning units in the textbooks shows that some grammar and/or vocabulary activities include female names, but those names act as the doers of actions. Figure 7 demonstrates the textbook used female names (Huda and Linda) to teach new vocabulary. Females describe the things they like or dislike. Similarly, Figure 8 shows the textbooks used a female name (Susan) to practice the use of propositions of time. (Circles were put on the female names in Figures $7 \&$ 8). Females are the doers of actions. These results provide an important insight that students are not instructed to consider the gender of audience in the broader ecology of the unit. Instead, female names are used to provide opportunities for students to practice the language.



Figure 7. An Example of a Vocabulary Activity from Traveller 1, p. 18

\section{PRACTICE}

Complete the sentences with prepositions of time.

1. Nasir is meeting Ali noon.

2. Paul always reads newspapers Sunday afternoon.

3. I usually drink a warm cup of milk the morning.

4. Hashim takes lots of photos his holiday.

5. Susan's graduation is

6. I was in Spain June.

7. My brother left ten minutes

Figure 8. An Example of a Grammar Practice Activity from Traveller 1, p. 18

\subsubsection{Parameter 6: Age of Audience}

The findings show $53.1 \%$ of writing prompts in the Traveller series do not provide information about the age of audience. It seems this finding did not reflect previous research which emphasizes the impact of audience age in writing a text (Cho \& Choi, 2018).

Furthermore, the findings display students have nearly similar opportunities to write for high school student age (22.4\%) and adult age (24.5\%) among given writing prompts. However, there is still a need to discover whether high school students in Saudi Arabia have a sense of audience awareness when writing for different ages because previous research has shown students may not write as successfully for different ages, as shown by Frank (1992). He instructed 30 fifth grade students to write a newspaper advertisement, but for two different audiences (a third-grade reader and an adult reader) to convince them to buy items. He found fifth grade students adapted writing according to their audiences; writing to a third-grade audience was more successful than to an adult audience. Frank states learners in fifth grade assume a third-grade reader's role because they are in a similar age 
group than an adult's role. This characteristic assists fifth grade students to meet the expectations of third grade readers. Also, it seems difficult to meet the expectations of an adult as students have not yetencountered adulthood. Frank's interpretation shows the audience's age plays a role in producing an effective text where fifth grade students succeeded in considering a third-grade audience's expectations more than an adult's.

The results illustrate writing prompts sometimes ask students to write to an adult reader. For example, one prompt instructs students to write a letter to Mr. Mansur (the father of a friend) providing suggestions about travelling to Saudi Arabia. By analyzing other language activities in the broader ecology of this learning unit, the investigation reveals the unit provides language activities related to the theme of this unit (travelling). For instance, in the speaking section, students discuss questions, such as: do you prefer a package holiday or an independent holiday? In the vocabulary section, students learn prepositional phrases to be used with location and distance. In the reading section, students read two passages about travelling abroad and answer reading questions. Clearly, these activities are connected to the above writing prompt that students address. This unit provides students with content knowledge and linguistic knowledge to write well. Nevertheless, these activities do not offer students with essential content for understanding how to write to an adult audience.

\subsection{Integration of Audience in Writing Sections}

As mentioned in the introduction section, the learning objectives of writing skills set up by the Ministry of Education for grades $10^{\text {th }}, 11^{\text {th }}$, and $12^{\text {th }}$ list audience as one of the major skills students should master.The analysis indicates the writing section provides information for students about how to address audience when they write a text. The following discussion presents four types of activities that develop a writer's sense of audience.

The first type of activity is discussion of a topic. As illustrated in Figure 9, students discuss two questions. The first has three aspects: how often students write letters, to whom they write, what the topic is. The second is how to communicate with a friend living in a different place. According to Traveller 6 Teacher's Manual, these questions trigger student background knowledge of a topic, and prepare them for responding to a writing prompt at the end of a writing lesson. In addition, the Teacher's Manual provides a suggested answer, as reflected in Figure 10. Overall, these results indicate the textbook does ask students to think about an intended audience (to whom they write a letter), but the examination of the Teacher's Manual exemplifies that textbook developers in Saudi Arabia offer no explanation for teachers on how to raise high school students' awareness of audience when they write letters. This is clear from the two purposes of this activity mentioned above and from the suggested answer. Other evidence is that the discussion of a topic frequently occurs at the beginning of each writing lesson, but it rarely presents questions related to the audience.

1. DISCUSS
- How often do you write letters? Who to? What about?

- How would you communicate with a friend who lives in another city or country?

Figure 9. An Example of a DiscussionActivity from Traveller 6, p. 16

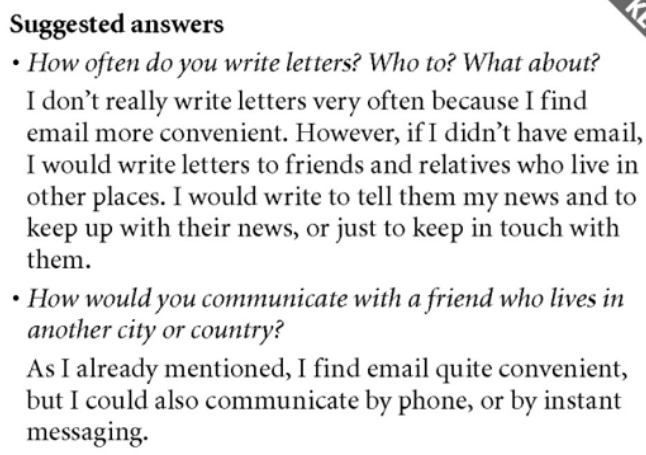

- How would you communicate with a friend who lives in another city or country?

As I already mentioned, I find email quite convenient, but I could also communicate by phone, or by instant messaging.

Figure 10. An Example of Suggested Answers from Traveller 6 Teacher's Manual, p. 19

The second type of activity is reading passages. The textbooks present a reading passageand then direct students to answer questions related to audience, for example:

Does the writer use certain vocabulary to make the text interesting for the reader? Does the writer use questions to attract the audience's attention? The writing activity in Figure 11 shows how a sense of audience has been integrated into a reading passage. This activity teaches students how the style and register of an e-mail/letter may differ according to the social status of an intended audience. The activity has two questions. Question A requests students to identify aspects of a semi-formal email. The email is written by David Huntington (a student in the school) to Mr. Garland (it seems he is a school principal). Question B directs students to consider how the style and register of the same email may be different if it is informally written to a friend or relative. This activity is excellent in bringing students' attention to the importance of an audience's social status in determining the style and register 
of a text. The activity shows writing an e-mail/letter to a school principal (who has a high social status) differs from writing an e-mail to a friend (who has an equal social status). The textbooks would have been more useful if awider range of such audience activities had been included in the textbooks because students will have various learning opportunities to develop a sense of audience. As a result, they may become a better communicator and appropriately address audiences of different social statuses.

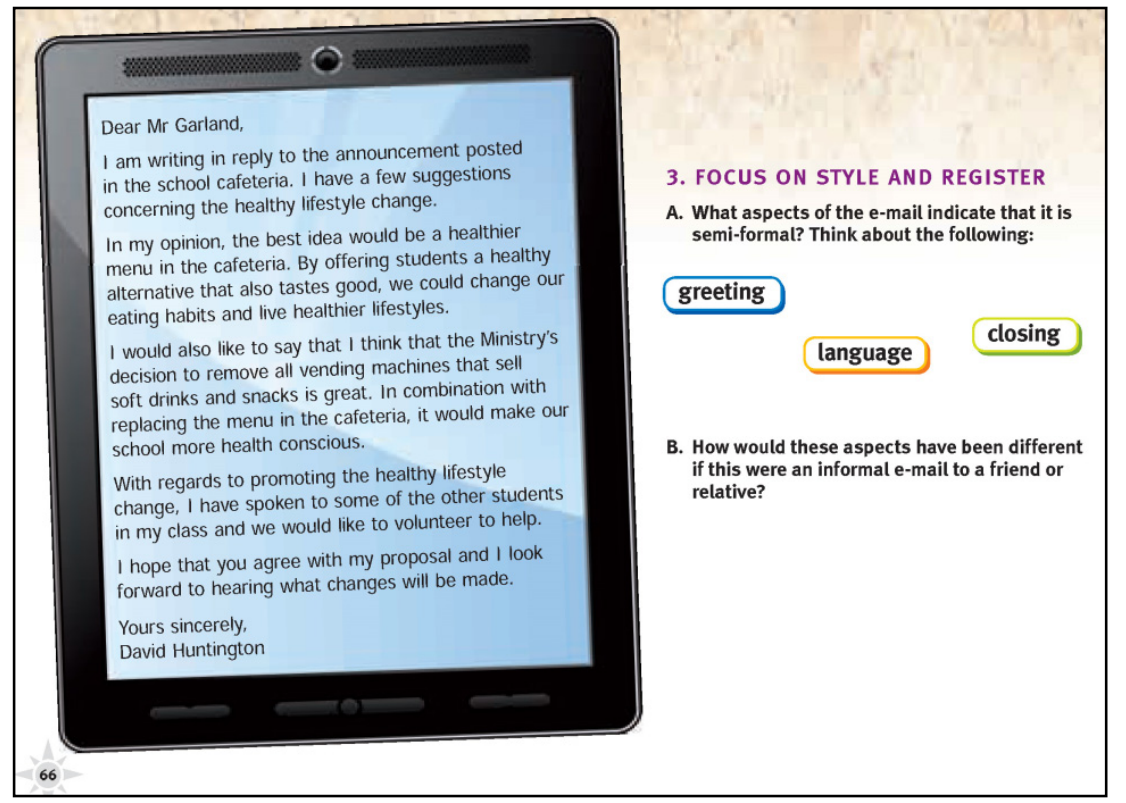

Figure 11. An Example Activity Integrating Audience in a Reading Passage in the WritingSection of Traveller 5 (p.

An outline is the third type of activity. The textbooks provide an outline, which has information for writing an introduction, body paragraphs, and a conclusion. Students follow it when they write a text. As depicted in Figure 12 , an outline recommends students to grab a reader's attention in the introduction paragraph through presenting topics in an attractive manner. However, this outline does not inform students how this can happen in the introduction paragraph. The TIP box, which follows this outline and is displayed in Figure 13, presents general suggestions for drawing a reader's attention when students write an article, but they are not specific to the introduction paragraph.

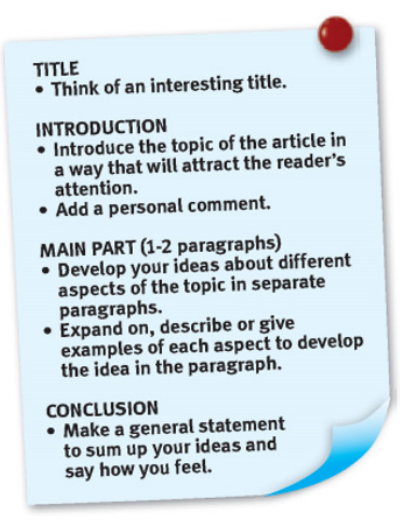

Figure 12. An Example of an Outline Activity from Traveller 3, p. 65

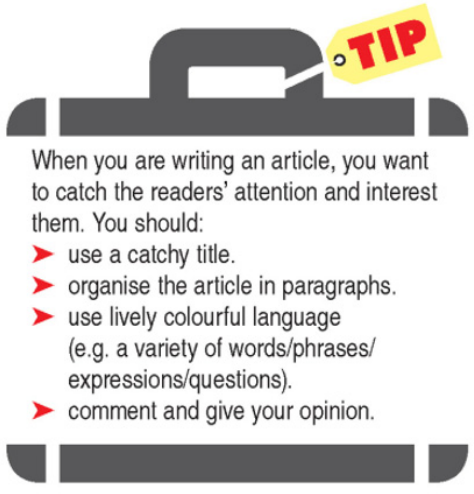

Figure 13. An Example of a TIP Box from Traveller 3, p. 65

The last type of activity is the TIP boxes (see Figure 14). At the end of each writing lesson, the textbooks often present a TIP box that includes suggestions on writing texts. This study found some TIP boxes suggest several ideas for students to appropriately address audiences. For instance, a student may use a catchy title to attract an audience's attention. The TIP box in Figure 14 explains to students how to write a report to two different audiences (superior or peers). Writing for a superior requires the use of a formal style. In contrast, writing for a peer requires the use of an informal style. This finding has a significant implication for the understanding of how an activity can increase a writer's sense of audience because students should adapt their reports according to the social 
status/closeness of an audience. This activity strengthens the idea that there is a relationship between the formality and informality of a text and an intended audience. In the literature, text formality has been associated with audience (Raimes, 1983; Hedge, 1988; Harmer, 2004). Therefore, the textbooks should includesimilar suggestions to boost students' awareness about the existing relationship between an audience and a text style.

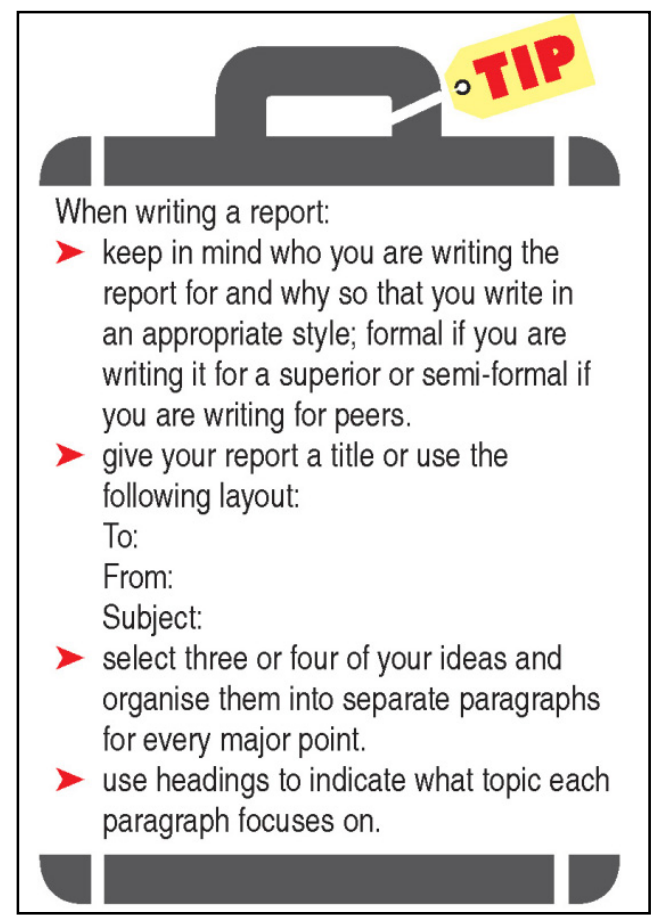

Figure 14. Integration of Audience in a TIP Box in the Writing Section of Traveller 6 (p. 75)

\section{Conclusion and Recommendation}

A sense of audience is fundamental in L2 writing (Cho \& Choi, 2018; Many \& Henderson, 2005). Without audience, one cannot deliver information. However, the literature review shows a lack of studies addressing a sense of audience in high school L2 textbooks, although it is of considerable importance in the development of student writing ability. Therefore, this study addressed this gap by examining to whom L2 students write based on a model of audience influence proposed by Grabe and Kaplan $(1996,2014)$ and two other parameters suggested by previous research. Writing prompts from six high school L2 textbooks in Saudi Arabia were collected and analyzed.

The results reveal writing prompts instruct students to write to a single reader and known/unknown readers. Also, students are repeatedly directed to write about general topics. These results suggest high school students have frequent learning opportunities to develop a sense of audience based on these three parameters offered in the Traveller series. However, the main limitation of the textbooks is the lack of context in which writing prompts in the Traveller series do not provide specific information about the gender, age, and social status of audience. For instance, prompts never direct male students to write for female readers. These results provide evidence that the lack of context in the writing prompts will not assist students in developing their audience awareness of gender, age, and social status. Furthermore, the examination of audience in the broader ecology of a learning unit reveals that audience-awareness instructions have been only incorporated in the writing activities and the TIP boxes offered in the writing sections of the textbooks, but they are uncommonly offered. The use of listening, reading, speaking, grammar, and vocabulary activities in a learning unit aims to improve student language skills and linguistic competence, but not a sense of audience.

To prepare students to have a sense of audience in L2 writing (Zainuddin \& Moore, 2003), textbook developers in Saudi Arabia need to improve writing prompt activities in high school English language textbooks. They need to increase the number of writing prompts that instruct students to write for the public, instead ofmainly focusing on the basic level of writing to a single reader. Furthermore, the results suggest the textbook developers should provide a clear context of writing for students.

Particularly, a writing prompt should include information about the age, gender, or social status of an audience. Although audience-awareness instructions have been successfully integrated in some reading activities and TIP 
boxes in the writing sections of a learning unit, instructions about audiences' social status and closeness should also be integrated in the writing prompts. For example, a textbook may provide opportunities to write for people who have high roles in the Saudi community. Students write a complaint letter to the Minister of Education to inform him about a problem they face in school. Or, they may write a thank you letter to the Minister of Health to praise free health services. These opportunities assist in developing a sense of audience social status, and as a result we could anticipate students may utilize a proper style and register to address different audiences.

Additionally, since prompts do not instruct male students to write for female students due to their local culture of gender sensitivity, a reasonable approach to tackle this issue, according to Turner (1990), could be to include a neutral gender language in the prompts, such as he/she or him/her. By doing so, this may create an image for students that a reader could be a male or female, not always a male.

L2 teachers should also have a role in teaching audience writing prompt activities effectively. They draw student attention to the differences in writing for known and unknown readers. As shown by Al- Mohammadi and Derbel (2015), undergraduate students in Oman were unableto address a foreigner due to the lack of audience awareness. Furthermore, although a few prompts in the Traveller series instruct students to write about Saudi cultural topics in an international magazine, teachers should pay close attention to the language and vocabulary that students use to write about specific topics. Al-Mohammadi and Derbel (2015) found students employed certain vocabulary and phrases in essays related to their own culture which are unfamiliar to a foreigner. Indeed, this shows students are unaware of foreigners'familiarity with other cultures.

To sum it up, with a caution of the interpretation of the study's findings, three conclusions can be drawn. First, this study adapted Grabe and Kaplan's $(1996,2014)$ model of parameters of audience influence, modified it, and utilized it to analyze writing prompt activities in L2 textbooks. Since the literature review shows research of high school L2 textbooks lacks a model of audience influence, the modified model may be used by other textbook researchers for a similar purpose. Second, this study provides evidence that textbook developers in Saudi Arabia provide frequent learning opportunities for students to write for a single reader and known/unknown readers. In contrast, they do not inform students about the gender, age, and social status of prospective audiences. Similar to Liao and Chen's (2009) conclusion about Chinese textbooks, it can be concluded that high school English language textbooks in Saudi Arabia are less audience-oriented because of three reasons. First, the writing prompts in the textbooks lack appropriate writing context regarding audience. Second, it appears that listening, reading, speaking, grammar, and vocabulary activities in the broader ecology of a learning unit aim to develop language skills and linguistic competence, not a sense of audience.

Third, audience-awareness instructions in the writing sections in a learning unit are insufficient. Lastly, this study has established a new gate of research on parameters of audience influence inwriting prompts in L2 textbooks, now it calls for future research on the same topic to broaden our knowledge about this significant matter in various EFL/ESL contexts.

\section{Acknowledgments}

I would like to express my heartfelt gratitude to my advisor, Dr. Stephanie Link, at Oklahoma State University for her guidance and support during this work. I wish to extend my special thanks to professors, Gene Halleck and An Cheng, who provided invaluable insight into the research.

\section{References}

Ahour, T., Towhidiyan, B., \& Saeidi, M. (2014). The evaluation of "English textbook 2"taught in Iranian high schools from teachers' perspectives. English Language Teaching, 7(3), 150-158. https://doi.org/10.5539/elt.v7n3p150

Al-Hajailan, T. A.-R. (1999). Evaluation of English as a foreign language textbook for third grade secondary boys' schools in Saudi Arabia. Mississippi State University.

Alhamlan, S. (2013). EFL curriculum and needs analysis: An evaluative study. King SaudUniversity.

Alharbi, A. (2015). A descriptive-evaluative study of a Saudi EFL textbook series. CogentEducation, 2(1), 1079946. https://doi.org/10.1080/2331186X.2015.1079946

Alharbi, A. A. M. (2017). Evaluation study for secondary stage EFL textbook: EFL teachers' perspectives. English Language Teaching, 10(3), 26-39. https://doi.org/10.5539/elt.v10n3p26

Aljouei, K. F., \& Alsuhaibani, Y. A. (2018). Evaluating "Traveller" English textbook series from Saudi secondary school EFL teachers' perspectives. English Language Teaching, 11(12), 138-153. https://doi.org/10.5539/elt.v11n12p138 
Almalki, M. M. (2014). Teacher perception of a new English as a foreign language (EFL)curriculum in Saudi Arabia.

Al-Mohammadi, S. A., \& Derbel, E. (2015). To whom do we write?: Audience in EFL composition classes. In R. Al-Mahrooqi, V. Thakur \& A. Roscoe (Eds.), Methodologies for Effective Writing Instruction in EFL and ESL Classrooms (pp. 197-208). IGI Global. https://doi.org/10.4018/978-1-4666-6619-1.ch012

Alptekin, C. (1993). Target-language culture in EFL materials. ELT journal, 47(2), 136-143. https://doi.org/10.1093/elt/47.2.136

Al-Qadi, H. M., \& Al-Qadi, K. R. (2015). A content analysis of the writing activities in Action Pack 10 to measure the degree of their congruence with the general grade outcomes for the English language guidelines in Jordan. European Scientific Journal, 11(22).

Alsharif, K. M. (2011). Towards quality teacher education: Productive pedagogies as aframework for Saudi pre-service teachers' training in mathematics education. Doctoral dissertation, Curtin University.

Al-sowat, H. (2012). An evaluation of English language textbook" Say it in English" for firstyear intermediate grade in Saudi Arabia. Journal of Studies in Curriculum and Supervision, 3(2), 332-413.

Aukerman, M., \& Beach, R. (2018). Student conceptualizations of task, audience, and self in writing college admissions essays. Journal of Adolescent \& Adult Literacy, 62(3), 319-327. https://doi.org/10.1002/jaal.888

Block, M. K., \& Strachan, S. L. (2019). The Impact of External Audience on Second Graders' Writing Quality. Reading Horizons: A Journal of Literacy and Language Arts, 58(2).

Britton, J., Burgess, T., Martin, N., McLeod, A., \& Rosen, H. (1975). School councilsresearch studies: The development of writing abilities. London: McMillan.

Brown, H. D. (2007). Principles of language learning and teaching (5th ed.). White Plains, NY: Pearson Education.

Cahyati, A. S., Srijono, D., \& Hum, M. (2018). An analysis on writing activities used in textbook entitled "When English Rings a Bell" For Seventh Grade Junior High School Based on The 2013 Curriculum. Universitas Muhammadiyah Surakarta.

Cho, Y., \& Choi, I. (2018). Writing from sources: Does audience matter? Assessing Writing, 37, 25-38. https://doi.org/10.1016/j.asw.2018.03.004

Cleary, S. (2003). The communication handbook: [a student guide to effectivecommunication].

Cleary, S. (2004). The communication handbook: A student guide to effective communication. Juta and Company Ltd.

Cohen, M., \& Riel, M. (1989). The effect of distant audiences on students' writing. American Educational Research Journal, 26(2), 143-159. https://doi.org/10.3102/00028312026002143

Dura, L. (2016). Audience and Young Bilingual Writers: Building on Strengths. Journal of Literacy Research, 49(1), 92-114. https://doi.org/10.1177/1086296X16683420

Economidou-Kogetsidis, M. (2010). Cross-cultural and situational variation in requestingbehaviour: Perceptions of social situations and strategic usage of request patterns. Journal of Pragmatics, 42(8), 2262-2281. https://doi.org/10.1016/j.pragma.2010.02.001

Ede, L., \& Lunsford, A. (1984). Audience addressed/audience invoked: The role of audience in composition. College Composition and Communication, 35(2), 155-171. https://doi.org/10.2307/358093

Saudi Ministry of Education. (2014-2020). English Language Curriculum for Elementary, Intermediate and Secondary Schools in theKingdom of Saudi Arabia Grades 4 to 12 [PDF].

Fielding, M. (2006). Effective communication in organisations. Juta and Company Ltd.

Fongoqa, N. V. (2002). The personal perspective essay in Xhosa as reflection of the writingcompetence of grade 12 learners. Stellenbosch: Stellenbosch University.

Frank, L. A. (1992). Writing to be read: Young writers' ability to demonstrate audience awareness when evaluated by their readers. Research in the Teaching of English, 277-298.

Grabe, W. (1990). Current developments in written discourse analysis. Lenguas Modernas, (17), 35-56.

Grabe, W., \& Kaplan, R. B. (1996). Theory and practice of writing: An Applied Linguisticperspective. Longman, New York. 
Grabe, W., \& Kaplan, R. B. (2014). Theory and practice of writing: An applied linguisticperspective. Routledge. https://doi.org/10.4324/9781315835853

Grave, W. (1990). Current developments in written discourse analysis. Lenguas Modernas, (17), 35-56.

Habib, A., \& Umar, H. (2006). A qualitative inquiry into the alignment of English textbooks with the national curriculum at secondary level. NUML Journal of Critical Inquiry (JCI).

Hammad, E. A. R. (2014). Palestinian EFL teachers' attitudes towards English textbooksused at the first three grades of elementary school. TESL-EJ, 18(1), n1.

Hanifa, R. (2018). EFL published materials: An evaluation of English textbooks for junior high school in Indonesia. Advances in Language and Literary Studies, 9(2), 166-174. https://doi.org/10.7575/aiac.alls.v.9n.2p.166

Harmer, J. (2004). How to teach writing. Harlow: Longman.

Harvey, A. (1997). The voices of the discourse of the problem of who says what in newsreports. The Journal of TESOL-France, 2(2).

He, L., \& Shi, L. (2008). ESL students' perceptions and experiences of standardized English writing tests. Assessing Writing, 13(2), 130-149. https://doi.org/10.1016/j.asw.2008.08.001

He, L., \& Shi, L. (2012). Topical knowledge and ESL writing. Language Testing, 29(3), 443-464. https://doi.org/10.1177/0265532212436659

Hedge, T. (1988). Writing. Oxford: Oxford University Press.

Henriques, S. (2009). An evaluation of English as a foreign language textbooks for secondaryschools in Angola. University of Kansas.

Hyland, K. (2001). Bringing in the reader: Addressee features in academic articles. Written Communication, 18(4), 549-574. https://doi.org/10.1177/0741088301018004005

Jahangard, A. (2007). Evaluation of the EFL materials taught at Iranian high schools. The Asian EFL Journal, 9(2), 130-150.

Johnson, D. M. (1992). Interpersonal involvement in discourse: Gender variation in L2 writers' complimenting strategies. Journal of Second Language Writing, 1(3), 195-215. https://doi.org/10.1016/1060-3743(92)90003-8

Johnston, H. (1996). Survey review: Process writing in coursebooks. ELT Journal, 50(4), 347-355. https://doi.org/10.1093/elt/50.4.347

Kobayakawa, M. (2011). Analyzing writing tasks in Japanese high school English textbooks:English I, II, and Writing. JALT Journal, 33(1), 27-48. https://doi.org/10.37546/JALTJJ33.1-2

Lee, H. (2013). The influence of social situations on fluency difficulty in Korean EFLlearners' oral refusals. Journal of pragmatics, 50(1), 168-186. https://doi.org/10.1016/j.pragma.2013.01.002

Liao, M. T., \& Chen, C. H. (2009). Rhetorical strategies in Chinese and English: A comparison of L1 composition textbooks. Foreign Language Annals, 42(4), 695-720. https://doi.org/10.1111/j.1944-9720.2009.01050.x

Long, R. C. (1990). The writer's audience: Fact or fiction. In Gesa Kirsch \& Duane H. Roen (Eds.), A sense of audience in writtencommunication (pp. 73-84).

Mangelsdorf, K., Roen, D. H., \& Taylor, V. (1990). ESL students' use of audience. In Gesa Kirsch \& Duane H. Roen (Eds.), A senseof audience in written communication (pp. 231-247).

Many, J. E., \& Henderson, S. D. (2005). Developing a sense of audience: An examination of one school's instructional contexts. Reading Horizons, 45(4), 3.

Midgette, E., Haria, P., \& MacArthur, C. (2007). The effects of content and audience awareness goals for revision on the persuasive essays of fifth-and eighth-gradestudents. Reading and Writing, 21(1-2), 131-151. https://doi.org/10.1007/s11145-007-9067-9

Mthembu-Funeka, W. N. Z. (2009). Genre-based approach to Isizulu home language education as a means to successful English first additional language education. 
Nelson, G. L., Carson, J., Batal, M. A., \& Bakary, W. E. (2002). Cross-cultural pragmatics: Strategy use in Egyptian Arabic and American English refusals. Applied linguistics, 23(2), 163-189. https://doi.org/10.1093/applin/23.2.163

Nunan, D. (1999). Second language teaching \& learning. Boston, Mass.: Heinle \& HeinlePublishers.

Raimes, A. (1983). Techniques in teaching writing. Oxford: Oxford University Press.

Ramanathan, V., \& Kaplan, R. B. (1996). Audience and voice in current L1 composition texts: Some implications for ESL student writers. Journal of Second Language Writing, 5(1), 21-34. https://doi.org/10.1016/S1060-3743(96)90013-2

Shaw, S. D., \& Weir, C. J. (2007). Examining writing: Research and practice in assessing second language writing. Studies in Language Testing, 26. Cambridge University Press.

Sheldon, L. E. (1988). Evaluating ELT textbooks and materials. ELT Journal, 42(4), 237-246. https://doi.org/10.1093/elt/42.4.237

Steer, J. (1988). Dialogue journal writing for academic purposes.

Tang, C.-H., \& Zhang, G. Q. (2009). A contrastive study of compliment responses amongAustralian English and

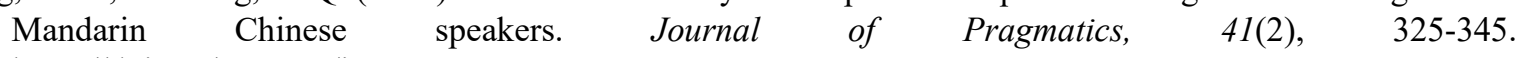
https://doi.org/10.1016/j.pragma.2008.05.019

Tawalbeh, A., \& Al-Oqaily, E. (2012). In-directness and politeness in American English and Saudi Arabic requests: A cross-cultural comparison. Asian Social $\quad$ Science, 8(10), 85. https://doi.org/10.5539/ass.v8n10p85

Turner, R. M. (1990). Gender-related considerations for developing the text of artinstructional materials. Studies in Art Education, 32(1), 55-64. https://doi.org/10.2307/1320400

Vandergriff, I., Barry, D., \& Mueller, K. (2008). Authentic models and usage norms? Gender marking in first-year textbooks. Die Unterrichtspraxis/Teaching German, 41(2), 144-150. https://doi.org/10.1111/j.1756-1221.2008.00019.x

Wiseman, A. W. (2010). The uses of evidence for educational policymaking: Global contextsand international trends. Review of Research in Education, 34(1), 1-24. https://doi.org/10.3102/0091732X09350472

You, X. (2004). "The choice made from no choice": English writing instruction in a Chineseuniversity. Journal of Second Language Writing, 13(2), 97-110. https://doi.org/10.1016/j.jslw.2003.11.001

Zainuddin, H., \& Moore, R. A. (2003). Audience awareness in L1 and L2 composing of bilingual writers. TESL-EJ, 7(1), 1-18.

Zohrabi, M., Sabouri, H., \& Behroozian, R. (2012). An evaluation of merits and demerits of Iranian first year high school English textbook. English Language Teaching, 5(8), 14-22. https://doi.org/10.5539/elt.v5n8p14 


\section{Appendix A}

An example of one full lesson in Traveller 1-Unit 1

\section{That's me}

\section{VOCAB ULARY}

PHRASES DESCRIBING LIKE AND DISLIKE Read the sentences. Which of the phrases in bold mean like and which dislike?

1. Tom is a big fan of Manchester United. He never misses a match.

2. Hamid can't stand reading late at night.

3. Alice is interested in art. She has twenty paintings in her house.

4. Huda is fond of children. She wants to become a teacher.

5. Henry finds science-fiction books boring. He rarely reads them.

6. Linda hates Geography. She never studies.

7. My brother and I are really into rock climbing. We go rock climbing every year.

\section{GRAMMAR}

PREPOSITIONS OF TIME

Read the dialogue and underline the prepositions of time. Then complete the table below with on, in or at.

Andy Let's meet tomorrow at 6:00.

Keith I'm afraid I can't. On Wednesdays I work from 10:30 till 6:30.

Andy $O K$, then. Do you want to meet in the evening, at around 8:00?

Keith Sure, and we can go to the new Italian restaurant. I went there two weeks ago and the food was delicious.

nine o'clock / the weekend

noon / night / midday / midnight

the age of five

the morning / the afternoon / the evening

August / autumn / 2008 / the 21st century

Tuesday / 4 July

a winter's night / a cold morning

a Sunday afternoon

\section{Other prepositions of time:}

during from ... to / till / until before after ago

\section{Grammar Reference p. 85}

\section{PRAC TICE}

Complete the sentences with prepositions of time.

1. Nasir is meeting Ali noon.

2. Paul always reads newspapers Sunday afternoon.

3. I usually drink a warm cup of milk the morning.

4. Hashim takes lots of photos holiday.

5. Susan's graduation is

6. I was in Spain

7. My brother left ten minutes

\section{INTONATION -)}

A. Listen and repeat. What do you notice about the stressing of in and at in the two sentences?

I sometimes read books in the evenings.

Let's visit Salman at the weekend.

B. Listen and repeat.

1. Saud worked from eight to seven last year.

2. There were no mobile phones in the 19th century.

3. I usually do housework on Mondays.

4. Jack called at noon.

\section{SPEAKING}

Talk in pairs about the things you like and don't like. Use some of the ideas in the box.

\section{I'm fond of jogging. \\ How often do you go jogging?}

About four times a week.

When do you find the time to go?

I usually go in the morning before I go to work.

What about you?

Oh, I hate jogging. I find it boring.

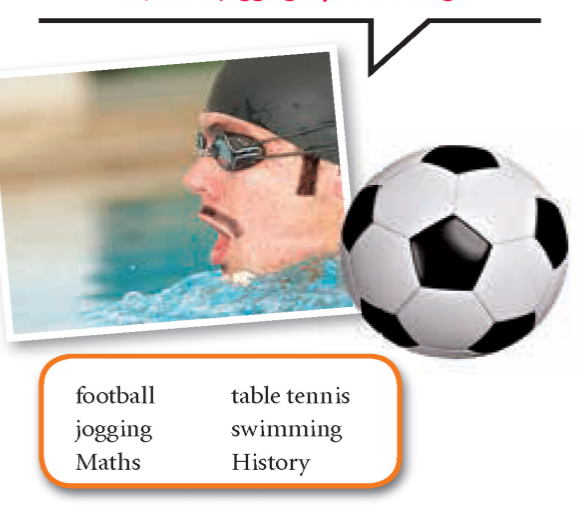




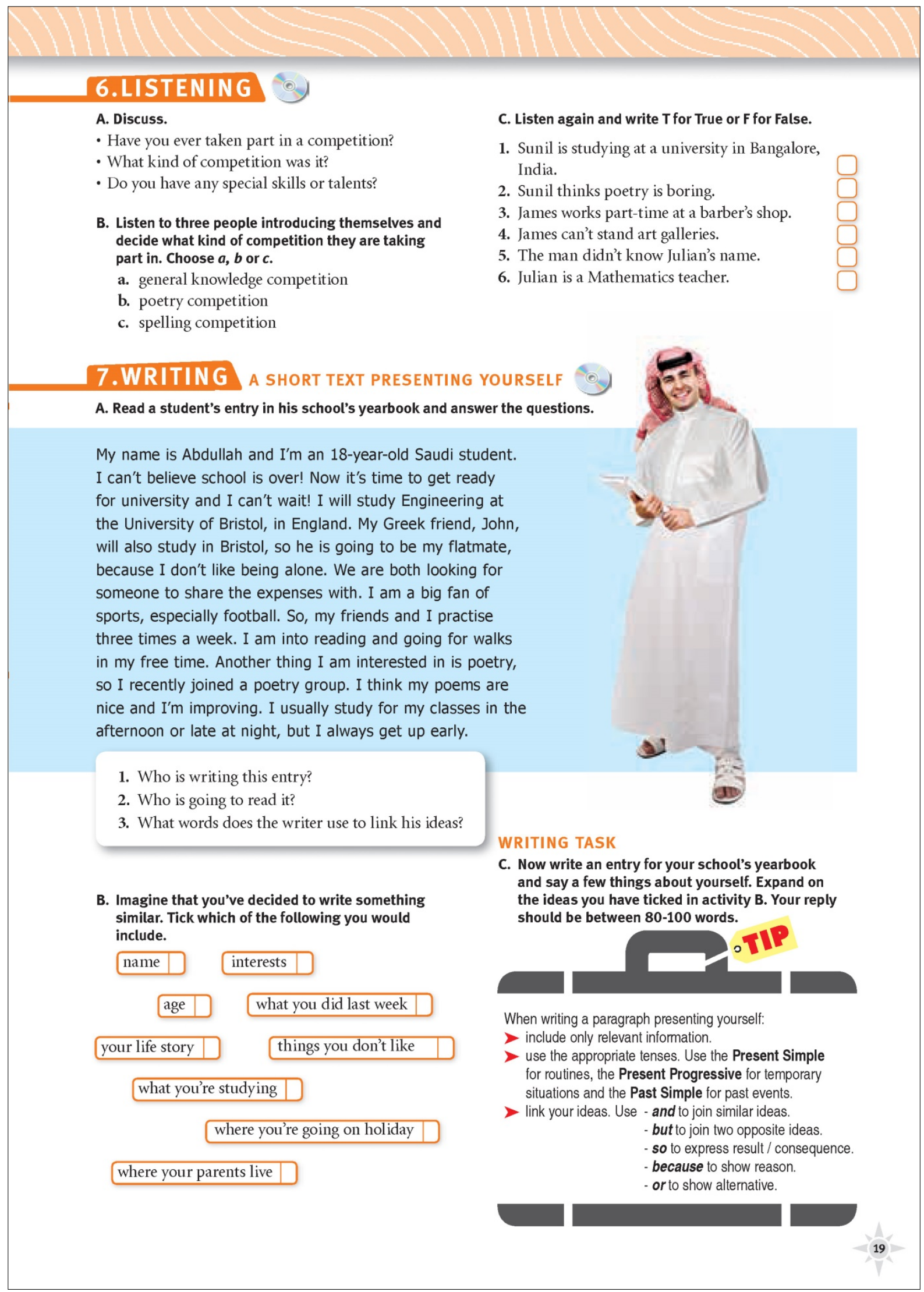




\section{Appendix B}

An example of one full lesson in Traveller 1-Unit 1

\section{1e Friendly faces}

\section{VOCABULARY}

ADJECTIVES DESCRIBING PERSONALITY Read the sentences below and match the words in bold with the definitions a-h.

1. I can't talk to Bill about anything. He's so quick-tempered!

2. One of Mark's bad qualities is that he's bossy. He keeps telling us what to do and what not to do!

3. Jake is so lazy. He just sits there all day doing nothing.

4. Don't be shy. Come and say hello to my family.

5. Bander is an outgoing person and loves meeting people.

6. My sister's an honest person. She never lies.

7. A very kind young man helped me carry my shopping bags up the stairs.

8. Ibrahim is a confident man, so job interviews are very easy for him.

a. not wanting to work / not very active

b. believing in yourself and your abilities

c. fond of telling people what to do

d. friendly, enjoying meeting other people

e. always telling the truth

f. afraid to meet or talk to other people

g. becoming angry quickly

h. helpful and friendly

Learn new words in context (in sentences describing situations). This way, it is easier to remember them.

\section{SPEAKING}

Talk in groups and discuss the following. Use the prompts in the box.

- What are your friends like?

- Do you always get along with them?

- Do you think you are a good friend?

- How can you describe the ideal friend?

\section{- My friends are...}

- We usually get along fine, but we sometimes argue about...

- I think/believe I am / am not a good friend because...

- The ideal friend should be...

\section{LISTENING -}

A. Listen to two people talking about three teachers. Match the people with the pictures.
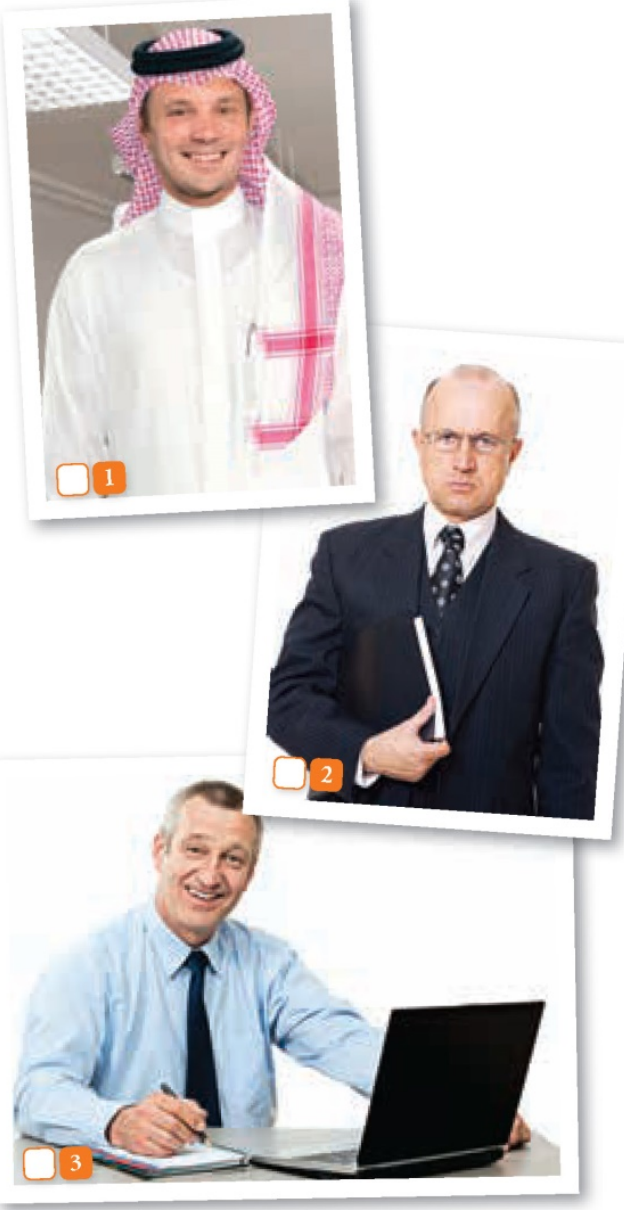
a. Mr Smith
b. Mr Green
c. Mr Khaled

B. Listen again and write $\mathrm{T}$ for True or $\mathrm{F}$ for False.

1. The two speakers are classmates.

2. Mr Smith teaches Mathematics.

3. $\mathrm{Mr}$ Green is not quick-tempered.

4. One of the speakers threw a bottle outside the window.

5. Both speakers hate Mathematics. 


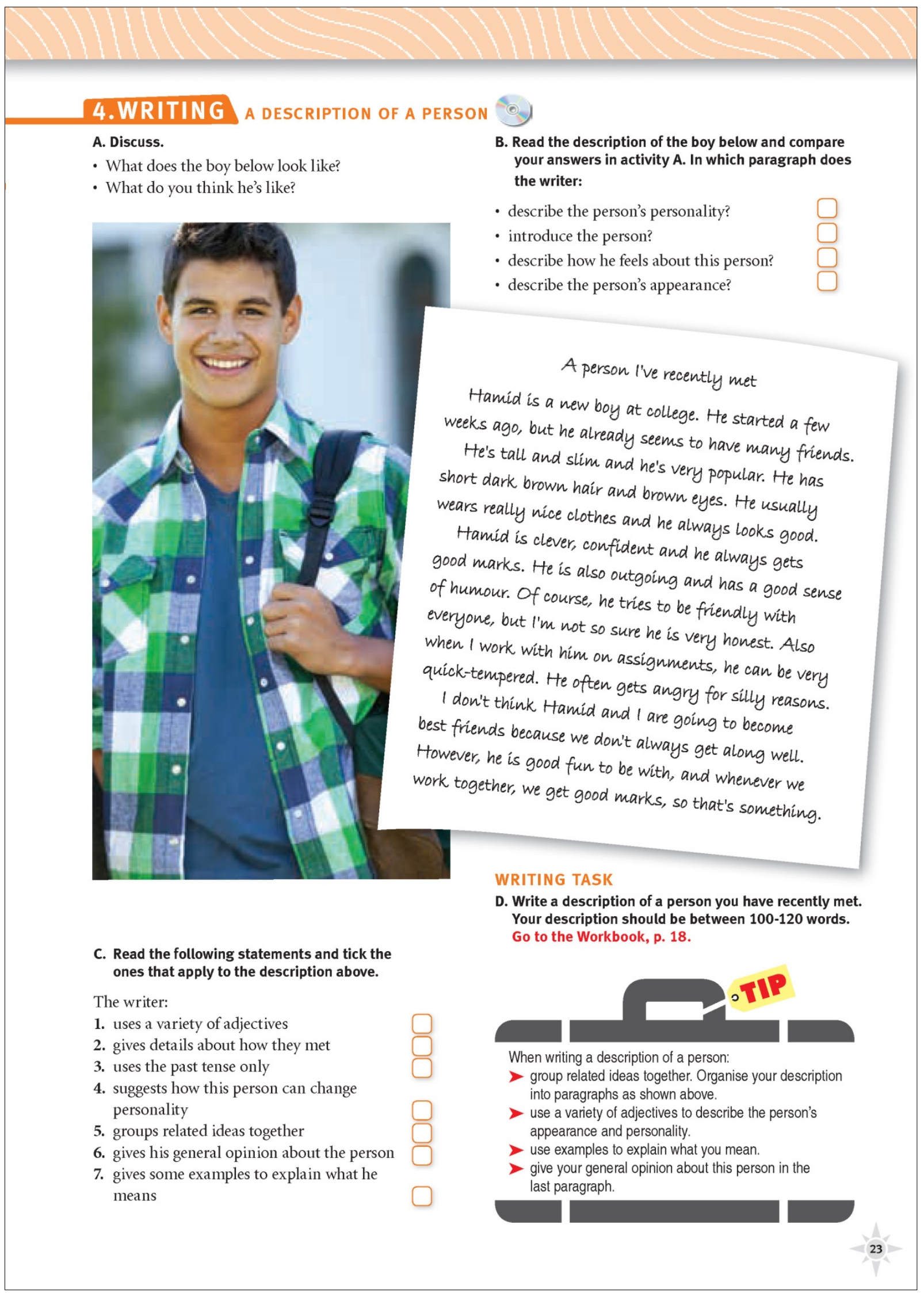


Appendix C

Parameters of Audience Influence Adapted from Grabe and Kaplan $(1996,2014)$

\section{Parameter 1: number of text readers}

(1) Oneself

(2) A single person (e.g., a teacher, a friend, a classmate, a relative)

(3) Small group

(4) Large group

(5) The public (e.g., magazine readers)

(6) Not mentioned

\section{Parameter 2: degree of social closeness}

(1) Known: reader is known to the writer (e.g., teachers, classmates, friends, relatives)

(2) Unknown: reader is unknown to the writer (e.g., strangers, magazine readers)

(3) Not mentioned: social closeness is not mentioned

\section{Parameter 3: degree of social status}

(1) Higher: reader has a higher social status than the writer (e.g., teachers, managers)

(2) Equal: reader has an equal social status to the writer (e.g., classmates, friends)

(3) Lower: reader has a lower social status than the writer

(4) Not mentioned: social relationship is not mentioned (e.g., magazine readers)

\section{Parameter 4: background knowledge of topics}

(1) General knowledge of topics

(2) Specific knowledge of topics:

2/A: Topical knowledge (chemistry, physics, etc.) 2/B: Cultural knowledge (Saudi Arabian culture)

Parameter 5: gender of audience

(1) Female: reader is a female

(2) Male: reader is a male

(3) Pronoun usage to indicate either gender (he/she)

(4) Not mentioned: gender of reader is not mentioned

\section{Parameter 6: age of audience}

(1) School age (e.g., elementary-high school)

(2) Adult age (e.g., a job manager, a teacher, a university student, a father of your friend)

(3) Not mentioned: age of reader is not mentioned (e.g., magazine readers) 


\section{Appendix D}

Example Coding of Writing Prompt Activities

Prompts from Traveller Textbooks

Parameters of Audience

NR SC SS BK GA AA

"Write a description of a person you have recently met. Your description should be between 100-120 words." (Traveller 1, p. 23)

"Write a review of a book you've recently read. Your review should be between 100-120 words." (Traveller 2, p. 29)

"A friend of yours has recently moved awayto another city. Write a letter to him/her with all your news (100-150 words)." (Traveller 3, p. 43)

"Write a description of a famous landmark or building in your country using the outlineabove (100-150 words)." (Traveler 4, p. 11)

$\begin{array}{llllll}6 & 3 & 4 & 1 & 4 & 3 \\ 6 & 3 & 4 & 1 & 4 & 3 \\ 2 & 1 & 2 & 1 & 3 & 1 \\ 6 & 3 & 4 & 2 & 4 & 3\end{array}$

"Read the rubric below and write your report (120-180 words). Go to the Workbook, p. 54. An international magazine is doing a feature on your town and wants to include information about healthy places to eat. You have been asked to write a report about one of the restaurants in your town.

Include the following information:

- where the restaurant is / the décor andatmosphere of the restaurant

- the variety and quality of the food

- the staff and the service in general" (Traveller 6, p. 75)

\section{Note}

1) Abbreviations of classification: number of readers (NR), social closeness (SC), social status(SS), background knowledge (BK), gender of audience (GA), age of audience (AA)

2) See the code numbers of parameters in Appendix $\mathrm{C}$

\section{Copyrights}

Copyright for this article is retained by the author(s), with first publication rights granted to the journal.

This is an open-access article distributed under the terms and conditions of the Creative Commons Attribution license (http://creativecommons.org/licenses/by/4.0/). 